\title{
Electronic Information Sharing in Local Government Authorities: Factors Influencing the Decision-Making Process
}

\author{
Alinaghi Ziaee Bigdeli, Muhammad Mustafa Kamal, Sergio de Cesare
}

\begin{abstract}
Local Government Authorities (LGAs) are mainly characterised as information-intensive organisations. To satisfy their information requirements, effective information sharing within and among LGAs is necessary. Nevertheless, the dilemma of Inter-Organisational Information Sharing (IOIS) has been regarded as an inevitable issue for the public sector. Despite a decade of active research and practice, the field lacks a comprehensive framework to examine the factors influencing Electronic Information Sharing (EIS) among LGAs. The research presented in this paper contributes toward resolving this problem by developing a conceptual framework of factors influencing EIS in Government-to-Government $(G 2 G)$ collaboration. By presenting this model, we attempt to clarify that EIS in LGAs is affected by a combination of environmental, organisational, business process, and technological factors and that it should not be scrutinised merely from a technical perspective. To validate the conceptual rationale, multiple case study based research strategy was selected. From an analysis of the empirical data from two case organisations, this paper exemplifies the importance (i.e. prioritisation) of these factors in influencing EIS by utilising the Analytical Hierarchy Process (AHP) technique. The intent herein is to offer LGA decision-makers with a systematic decision-making process in realising the importance (i.e. from most important to least important) of EIS influential factors. This systematic process will also assist LGA decision-makers in better interpreting EIS and its underlying problems. The research reported herein should be of interest to both academics and practitioners who are involved in IOIS, in general, and collaborative e-Government, in particular.
\end{abstract}

Keyword: Electronic Information Sharing, Information Integration, G2G Collaboration, Local Government Authority, Socio-Technical Factors

\section{INTRODUCTION}

The enormous usage of Information and Communication Technologies (ICTs) has altered different aspects of life; how people live, how businesses run, and how governments interact with their citizens. Recently, the adoption and development of these technologies in private sectors has put massive pressure on public sectors to keep up with the same pace. Governmental organisations discover that it is essential to transform their administrative processes in order to improve the efficiency and effectiveness of interacting with their citizens (Tan and Pan, 2003). One such transformation is the use of ICT to facilitate government information sharing in a networked environment. The ability to share information within and among governmental organisations is vital to transform the organisational structure and communication channels between and among different agencies in order to deliver services towards citizens in an efficient manner. Electronic information sharing across government boundaries requires fundamental technical and organisational changes (Pardo et al., 2006). Therefore, to have an effective and sustainable EIS, governmental organisations need to overcome a range of problems and challenges. From a technical point of view, information system developers are faced with a variety of challenges related to the existence of different platforms, diverse data structures and incompatible network infrastructures (Pardo et al., 2006). From an organisational perspective, enabling information sharing requires new work processes among the organisations, leading to a considerable change in organisational structure and culture (Fountain, 2001). Identifying these challenges is the first step of understanding the complexity and socio-technical nature (Luna-Reyes et al., 2005) of information sharing across organisational boundaries. Therefore, the main objectives of this paper are summarised as follows: 
- Identify the factors influencing EIS in Government-to-Government (G2G) collaboration.

- Present a conceptual framework in order to illustrate clearly the social and technical nature of the phenomenon.

- Justify and evaluate the importance of the proposed factors by conducting two case studies in LGAs in the United Kingdom (UK). It may not be sufficient to merely focus on different factors in developing an understanding for EIS in LGAs. Thus, identifying the importance of the proposed factors may provide a greater insight and responsiveness whilst EIS.

The importance of influential factors to EIS has been taken into consideration as a gap in literature. The intent herein is to offer LGA decision-makers with a systematic decision-making process i.e. from identifying the influential factors (conceptual findings) to prioritising their importance based on the views of the decision-makers in LGAs (empirical findings). This systematic decision-making process is aided by applying the AHP technique. The authors argue that this is one of the most appropriate technique in which plethora of research supporting that AHP can be used to prioritise the factors based on their importance (e.g. Khoo et al., 2002; Salmeron and Herrero, 2005; Kamal and Alsudairi, 2009; Kamal et al., 2012). Therefore, AHP can support the decision-making process as it may result in more informed practices and as a result, provide a deeper understanding of EIS factors. This technique is significant as it: (a) may enhance the analysis of EIS in LGAs, (b) extend the existing models on EIS by incorporating an AHP technique, (c) tests and justifies the feasibility of the AHP technique through multiple case studies, (d) reduces complex decisions through series of pairwise comparisons and then synthesizing the results, and (e) facilitates LGAs in realising the importance of EIS factors. The remainder of the paper is structured as follows. In the following section, we describe the theoretical background on information sharing and integration. Afterwards we narrow down the research by focusing on electronic information sharing (EIS) in local government authorities. The research methodology, including the justification for utilising AHP technique will then be presented followed by the presentation of the case organisations. The discussion based on the findings is presented followed by lessons learnt. Conclusions, limitations and future recommendations are summarised in the last section.

\section{LITERATURE REVIEW ON INFORMATION SHARING AND INTEGRATION}

A number of academics have clarified that in order to gain the maximum benefits of using ICTs in government processes, organisations within a government are required to integrate and share their information. Dawes (1996) simply defines information sharing as exchanging information within and across government agencies or otherwise giving them access to information. Since single and dependent organisations within a government cannot deal and solve complex problems related to service delivery alone, managing public services increasingly relies on multiple networks of interdependent organisations. Scholl and Klischewski stated that information integration can be recognised as "the forming of a larger unit of organisational entities, temporary or permanent, for the purpose of merging processes and/or sharing information" (Scholl and Klischewski, 2007: 897). Therefore, information integration is a pre-requisite of information sharing.

Gil-Garcia et al., (2009) clarified that inter-organisational information integration and sharing is a combination of both social and technical elements hence it is a very complicated field to study. They suggested four interconnected factors ranging from social to technical which would help for a comprehensive understanding of the concept: (1) trusted social network, (2) shared knowledge and information, (3) integrated data, and (4) interoperable technical infrastructure. Trusted social networks refer to a set of collaborations between those actors who are involved in inter-organisational information sharing and who trust each other as the fundamental stage of exchanging information. Shared information and knowledge refer to the flow of tacit and explicit knowledge in the form of formal documents, information relationships, messages, emails, etc. Integrated data indicates the integration of data at different levels based on an agreed standard among networked organisations. Lastly, the interoperable technical infrastructure is defined by different information systems which are 
able to communicate with each other and transfer information. A review of the literature indicates that research on inter-agency electronic information integration and sharing, especially in the public sector, is very limited. In general, previous research has focused on a combination of electronic and non-electronic information sharing and can be divided into three main contexts: (a) intraorganisational, (b) inter-organisational, and (c) interagency (Akbulut et al., 2009). In the intraorganisational context, prior research has mainly focused on analysing individuals' intention to share information/knowledge within an organisation. In the inter-organisational context, studies have acknowledged the importance of information sharing as a booster of networked collaboration in supply chains (e.g. Guo et al., 2006; Kelle and Akbulut, 2005).

In the interagency context, only two detailed studies were identified. The earliest research conducted at this level was a study by Sharon Dawes (1996). Dawes carried out a survey in the state of New York and analysed the attitude and thoughts of 173 government managers regarding the identified benefits and barriers of information integration and sharing. Around $80 \%$ of the State's managers identified that information sharing among different agencies brings beneficial results. They considered the following as the most important benefits: (a) more integrated plans, (b) improvement in policy development and programme implementation across agencies, (c) more accurate data and information for decision-making and problem solving, (d) improvement in using the resources, and (e) improving the networked collaboration among the agencies. Around $40 \%$ of the participants in the study clarified that they were concerned about the risk of adopting information sharing in their organisation. They believed that information integration and sharing could lead to a decrease of the level of managers involvement in decision-making and also result in possible data misinterpretation across the agencies. Moreover, they stated that since information integration brings transparency to the organisations processes, criticism by citizens and businesses is inevitable. The study showed that successful information integration and sharing in public sectors depends on two main issues; (1) establishing a legal and formal framework which can guide the information integration and sharing activities such as interagency agreements and common legislation for the authorities, and (2) effective tools to ease the management of the shared public information such as information inventory, technical standards and common data definition. Based on the findings of the surveys, Dawes (1996) proposed a theoretical framework of interagency information sharing which is illustrated in Figure 1.

\section{INSERT FIGURE 1 HERE}

This model proposes that the main driver of interagency information sharing is the pressing problems that might be solved through information sharing among the organisation. It also argued that the decisions of agencies on whether they should adopt and participate in information sharing or not is strongly dependent on their perceived risks and benefits, while the deployed policy and management framework is inevitable. Sharing experience, consequently, is generating the basis of actual benefits and risks and could be a lesson for the future policy and management framework. The model by Dawes provides a foundation for understanding information sharing by highlighting that sharing experiences should be used to identify the actual benefits and risks. It also emphasises that a policy and management framework should be in place to promote the benefits and mitigate the risks. However, the framework is limited in two aspects. Firstly, the survey was conducted in the 1990s when information technologies were not as advanced and developed as they are today. Therefore, it fails to consider and capture the technological factors which facilitate interagency information sharing in an electronic manner. Secondly, the model does not differentiate between electronic and nonelectronic information sharing. This issue is fairly important as the expected benefits and risks differ in electronic and non-electronic information sharing.

The second study was conducted by Landsbergen and Wolken (2001). This study mainly focused on electronic interagency information sharing, building upon the theoretical model proposed by Dawes in 1996. The researchers reviewed a variety of prior studies on information system interoperability, information resource management, and networked collaboration in the public sector. They identified the costs and benefits of adopting interoperability in the public sector and a list of barriers was created 
in order to propose their expanded model of electronic interagency information sharing. Landsbergen and Wolken selected two different case studies - one focusing on environment reporting and the other concentrating on Geographic Information Locator Service (GILS). They interviewed federal and state officials in five states (Kansas, Massachusetts, Ohio, Texas, and Washington). Based on the result of the gathered data, they proposed an extended model of interagency information sharing as shown in Figure 2.

\section{INSERT FIGURE 2 HERE}

The authors argued that in Dawes's study the agencies participated because they were motivated by a set of tangible benefits, as well as a strong political pressure to share their information. They criticised that these factors (i.e. political pressure to share information) would not be sufficient to provide a response to a broad range of circumstances especially with the rapid pace of technological change. In relation to these arguments, Landsbergen and Wolken (2001) recommended that as well as developing harmonised managerial, legal, and policy approaches, a technological infrastructure would be inevitable to support and facilitate information sharing. The main contribution of their model therefore is its emphasis on the need for a technological infrastructure along with a legal, managerial, and policy infrastructure to maintain and support interagency information sharing via electronic means. Despite the extension, the model is limited in one significant respect. Landsbergen and Wolken (2001) focused on recognising the experiences and viewpoints of those government agencies that were pioneers in using technology and complex systems rather than those agencies who may not have been familiar with such initiatives. As a result, the findings of their study cannot be generalised to government agencies that are unaccustomed to electronic information sharing.

Several information integration and sharing development projects fail to deliver the expected benefits. A large percentage of these failures are the result of social and organisational factors, rather than just technical issues. Conceivably, a significant problem facing system developers is that the organisational impacts resulting from the implementation of an information system are undesirable and unpredictable (Doherty and King, 2005). Since sophisticated and complex information systems can interact with the host organisation in very different ways, it would be very difficult to predict all of their impacts. Clegg et al., (1997) noted that the lack of attention to human and organisational factors is a key reason of system failure in organisations and is manifested in poor project management, poor examination of user requirements and failure to involve the key stakeholders. While, in recent years, several studies have identified and analysed a variety of environmental, interorganisational and intra-organisational factors affecting governmental inter-organisational information sharing, they do not provide a comprehensive set of factors involved. Most of the frameworks and models (e.g., Dawes's conceptual model) specifically focused on interagency information sharing at the State level (i.e., American State). Although there are some similar issues regarding electronic information sharing between central and local governments, an investigation which specifically focuses on electronic information sharing in local government agencies is essential. Local government agencies are not just the scaled-down version of central government as their human, financial, and technological resources are more limited compared to central governments. Furthermore, previous research (e.g. Lee and Rao (2007), and Gil-Garcia et al. (2007a)) is mainly focused either on technical issues and factors involved in information sharing or managerial and organisational factors. Therefore, further research is required in order to identify and justify the factors influencing information sharing in LGAs.

\section{PROPOSED CONCEPTUAL FRAMEWORK}

Since the LGAs are the front office of central government with the responsibility to develop and supply diverse services to citizens and business, integration and sharing of information within agencies become inevitable. LGAs have quite complex organisational structures and basic service delivery systems based on their resources and their customers' needs (Senyucel, 2005). LGA service delivery and administration processes have been traditionally based on a decentralised bureaucratic framework. As the result of this bureaucratic structure and the fact that local government 
administrators and employees do not have an in-depth knowledge and experience of information technology, IT implementation and adoption become a slippery slope (Beaumaster, 2002). There is a constant pressure from central government, the public and the press on LGAs to make use of a wider range of information technologies to be able to enhance operational efficiency and effectiveness. Beaumaster (2002) argues that LGAs suffer from what may be termed as "IT lag time". This means there is a large gap between the adoption of new technologies (i.e. information integration and sharing) and their acceptance and reutilisation across the entire organisation. Therefore, regarding the adoption of new IT solutions, local government agencies are categorised as the late majority groups or "laggards" (Themistocleous et al., 2004). Rogers $(1983 ; 1995)$ indicates that laggards are those who adopt new technology when it is necessary and there is no other choice. Among the laggards, the decision on whether to use and adopt new technology or not is fairly time consuming as their social and technological resources are very limited. These groups would wait until the new technology will be widely tested, adopted and standardised. It can thus be argued that adoption of information integration and participation in EIS (as new initiatives in public sectors) by LGAs does not significantly differ from other information technology adoption among LGAs. However, there are very limited publications and cases regarding the participation in electronic information sharing in local government agencies. This shows that the level of willingness to participate in this initiative is fairly low.

While the importance of considering both technical and organisational factors in any IT/IS project, (including information integration) has now been acknowledged (e.g. Doherty and King, 2005), little progress has been made in order to develop a socio-technical framework so as to identify and analyse the range of factors from social to technical. One of the few examples is the survey conducted by the Centre of Technology in Government (CTG) at the State University of New York. The researchers in the CTG centre viewed information sharing and integration as a combination of four different but interrelated contexts; Policy and Social Environment, Inter-organisation Setting, Organisation/Business Process Layer, and Technology Solution. Based on this perspective, the solution should be built based on considering intra-organisational interaction and processes such as business processes, decision-making processes and so on. Subsequently, since the organisation needs to collaborate and cooperate with other entities within the larger organisation, the intra-organisational issues are affected by elements of the larger multi-organisational settings such as leadership participation, trust, etc. Also, at a macro level, the inter-organisational relationships are influenced by factors in their shared environment such as political and economic issues. Based on this discussion, we can recognize that information integration and sharing should be viewed as a multi-disciplinary notion (Pardo and Tayi, 2007). However this approach has not been tested practically at a local government level; it might assist the key stakeholders, and IT developers to move away from a traditional organisation structure and boundaries and consider all factors affecting Inter-organisational Information Sharing (IOIS). Therefore, it would be positive to investigate these layers in depth.

\section{Policy and Social Environment}

This layer refers to a regulatory framework which defines the scale, content, and standards of electronic information sharing among governmental agencies based on formal policies and regulations. This includes those external factors which have strong institutional influences on interagency information sharing such as legislation and policy concerns, as well as the economic and political situation (Pardo and Tayi, 2007). Since most governmental activities are identified and funded through formal legislations and policies, a consideration on bureaucratic and political factors is required (Pardo and Tayi, 2007). By and large, these legislations force the agencies to focus on their own activities rather than cross-boundary collaboration and cooperation. As Landsbergen and Woken (2001) stated, governmental agencies typically gather, process, and store information regarding those activities in which they are involved while they are not aware of the circumstances in which they can share data and information with other agencies. Moreover, political and economic issues have been identified as two key environmental factors affecting any e-Government development project (Heeks, 2006). This applies to IOIS project as interdependent groups (e.g., senior public managers, politicians, IT developers, etc.) with different objectives, values, and political backgrounds are involved in the 
same project. From an economic point of view, since the benefits of information sharing among different government agencies are still hidden and unclear, governments prefer to spend their budget on other IT-related projects. In addition, developing and implementing such projects is quite costly as it requires bringing together both tangible (people, money, equipment, etc.) and intangible (data, information, etc.) resources. In turn, governmental entities lose their willingness of carrying out these projects. Furthermore, network externalities would strongly affect the adoption of information sharing and integration within an organisation and they refer to "the positive external consumption benefits as a result of a technology use" (Lou et al., 2000: 94). This means a user of new technology will benefit more as the total number of users for the technology increases. Therefore, a rise in users puts pressure on those organisations that have not yet adopted the technology. As interagency information integration and sharing involves two or more agencies to collaborate, network externalities should be recognised as a key issue to attract more agencies to participate in the notion.

\section{Inter-Organisational Setting}

The notion of sharing and integrating information within public and private organisations strongly depends on inter-organisational relationships and network collaborations (Pardo and Tayi, 2007), (Philip and Pedersen, 1997). Formation of these networks has been identified as a complicated process as the goals and objectives are quite diverse among different departments. The entities involved might have different interests, expectations and goals (Navarrete et al., 2010). This lack of shared goals and objectives within the government departments can be identified as a primary challenge to information integration and sharing projects, possibly leading to confusion and conflict among different roles and responsibilities. Therefore, the success of inter-organisational information sharing and integration is associated with clearly defined goals for each department.

Leadership can be identified as another key factor concerning information sharing and integration (Faerman et al., 2001), (Gil-Garcia et al., 2007a), (Zheng et al., 2009). It refers to the task of managing the collaboration process. Leadership at all levels plays a significant role in order to define the rules and situations for the individuals involved. Four major tasks for managing and maintaining collaboration networks have been identified: activating, framing, mobilising, and synthesizing (Agranoff and McGuire, 2001). Activating refers to the identification of participants and stakeholders in the network. The process of framing involves defining the operating rules of the network. Mobilising encourages individuals to make an efficient commitment to the network. Finally, synthesizing is the task of improving the condition for having a productive interaction and collaboration among the network. Leaders can use their power and reputation to legitimise ways to deal with and solve problems. Participation in inter-organisational information sharing is also strongly dependent on trust among different departments and entities (Pardo and Tayi, 2007 and Gil-Garcia et al., 2010). Anderson and Narus (1986) in Neergaard and Ulhoi (2006: 522) define inter-organisational trust as "a company's belief that another company will perform actions that will result in positive outcomes, as well as not taking unexpected actions that would result in negative outcomes for the company". Building trust can be seen as a significant step in order to establish successful interorganisational information sharing. The result of empirical analyses by Zaheer et al., (1998) clarify that inter-organisational trust reduces negotiation cost and conflict and increases performance among different sections involved in information sharing. In addition, financial matters would certainly influence EIS participation in the public sector. On the one hand, a governmental agency could face some difficulties related to obtaining the level of funding requested, and on the other hand, they should deal with the complexity of the funding allocation (Lam, 2005). For participating in electronic information sharing as an organisational innovation, financial capability is inevitable for procuring and developing adequate levels of hardware and software as well as for improving the level of IT knowledge among the employees (Kim and Bretschneider, 2004).

\section{Business Processes}

In general, information systems have a strong influence on the work processes of organisations as these systems embed the processes and information flows in complex software (Pardo and Tayi, 2007). Information sharing and integration involves mutually adjusting work processes of multiple 
organisations. It requires not only a technical transformation, but also change in decision-making policies and in the mind-set of the employees. Therefore, change in processes, functions and management mind-set, especially in the public sector, represents a key issue (Lam, 2005). However the development and adjustment of separate processes, information flows, and workflows is an extremely complicated task, resulting in a significant rise in overall integration cost as the integration time and maintenance would be reduced.

\section{Technology Solution}

From a technology point of view, developing inter-organisational information integration and sharing is a complicated task as it involves complex systems composed of different software, hardware, and telecommunication technologies. Participation in such projects requires a certain level of IT infrastructure, knowledge, and capability among the involved organisations (Fan and Zhang, 2007). Moreover, accessing and sharing information from diverse sources such as different databases, text files, images, etc. would cause severe problems. Solving these technical problems typically involves developing data standards, constructing systems of ontologies and designing interoperable applications to provide a structure for alignment of meaning across heterogeneous and unstructured resources (Pardo and Tayi, 2007). Lack of interoperability standards and disparities in architecture are a noticeable concern among information sharing projects (Lam, 2005). Sharing and integrating large amounts of data with different forms, from different organisations with different geographical locations, and different technological platforms also poses numerous challenges regarding other technical factors such as data quality, security, accuracy, consistency and completeness. Perhaps, one of the most significant challenges for developing such a project is application security. It is vital not just for improving the work and information flow between different agencies and departments, but also for building confidence and trust among them.

The factors affecting inter-organisational information sharing have been summarised in Figure 3. As we discussed before, these factors, which are either technical or social in nature, should be viewed holistically. As with other IS projects, the expected performance of EIS among organisations requires the consideration of perceived benefits, risk, and barriers (Gil-Garcia et al., 2007b). The benefits refer to the potential achievement of participating in EIS which can play an important role as a driver for participation. Reduced cost and increased productivity, accuracy of information, completed information for decision-making and improvement of networked collaboration among governmental organisations are some examples of perceived benefits of electronic information sharing (Fan and Zhang, 2007). Furthermore, there are certain risks of information sharing among different organisations, as the information collected by one department would be available to others to access and use. One of the main concerns is that information sharing and integration in the public sector will increase evaluation or criticism as it makes governmental organisations more transparent. As a result a large number of departments are concerned about sharing their information as they might be questioned about the accuracy and validity of the shared information.

\section{INSERT FIGURE 3 HERE}

\section{RESEARCH METHODOLOGY}

The proposed research methodology for this research is based on three phases namely: research design, data collection and data analysis (Jankowicz, 2000), as presented in Figure 4 (this figure further clarifies the whole research conducted in this paper). As the current research attempts to validate the conceptual framework (Figure 3), an interpretive, qualitative case study approach is used to test the proposed framework. Interpretivism was adopted, as the aim of this paper is to test the importance (i.e. by using the AHP technique) of factors influencing EIS among LGAs. Interpretivism assumes that the knowledge of reality is gained only through social constructions such as consciousness, shared meanings, language, documents, tools and other artefacts (Saunders et al., 2000). It is also anticipated that as the social world cannot be reduced to isolated variables, such as space and mass, it must be observed in its totality. Thus, a research approach that may allow LGAs to 
be viewed in their entirety and permit the authors to get closer to the interviewees, gain their viewpoints and interpret their perceptions becomes a requisite. Hence, interpretivism is considered as more appropriate for the research reported herein.

\section{INSERT FIGURE 4 HERE}

Qualitative research is multi-method in focus, involving an interpretive, naturalistic approach to its subject matter (Denzin and Lincoln, 1994). The rationale for selecting the current research methodology is that when an area of science is involved with human and organisational idiosyncrasies, qualitative research methods should be used (Remenyi and Williams, 1996). Other reasons for suggesting a qualitative approach as more appropriate are to:

- Investigate less acknowledged phenomena like IOIS in LGAs,

- Examine the complex processes, e.g. analysing the importance of factors influencing the decision-making process for EIS among LGAs,

- Examine the phenomenon in its natural setting,

- Provide considerable flexibility during interviews and observations, and

- Learn from practice.

A case study examines a phenomenon in its natural setting, employing multiple methods of data collection to gather information from one or a few entities, e.g. people, groups, or organisations (Yin, 1994). In the context of this paper, the authors focused on multiple-case study - i.e. conducting two case studies (hereafter referred to as LGA_North and LGA_East from the region of England - for confidentiality reasons the coded names are used to refer to these entities). Case studies enable the researchers to investigate a phenomenon in depth, getting close to the phenomenon, providing rich primary data and revealing its deep structure within the organisational context (Cavaye, 1996).

In addition to the interviews, data was collected through several other sources like observation, minutes for meetings, consultancy reports, the official website of the individual case organisation and archival documentation based on a detailed questionnaire. Interviews are regarded as the main tool of qualitative research for data collection process. In this research, interviews constituted the main data source in the case organisations. Three participants from both LGA_North and LGA_East were interviewed using structured interviews. Structured interviews were based on the interview agenda that lasted from $1 \frac{1}{2}$ to 2 hours each. Using the interview agenda, the interviewees replied to specific questions regarding EIS participation. Semi-structured interviews with the same participants also took place but with a more flexible agenda and these interviews lasted for an hour. With this type of interviews the participants attempted to further clarify some issues that derived from the structured interviews. All the structured and semi-structured interviews took place at interviewees' offices. Unstructured interviews (between 30 minutes to 1 hour) dealt with discussions that the authors had with interviewees but without using a structured or semi-structured type of interview. The unstructured interviews were carried out during lunches, coffee breaks and out of office hours. Using unstructured interviews some important data regarding the case studies were collected. All of the interviews were tape recorded and transcripts prepared as soon as possible after each individual interview. Tape recording supported in collecting accurate data and interpreting them without time pressures. In the analysis of the case study, a pattern-matching logic was employed. This technique compares an empirically based pattern with a predicted one (Yin, 2003). Therefore, as we first formed the conceptual framework (Figure 3), this technique would be appropriate to compare the data from the literature (predicted ones) with the data gathered from the interviews (empirical ones). Prior to analysing the data, a summary of each interview transcription as well as draft of each case study were sent back to the relevant interviewee in order to final review. The results and analyses were also reviewed by the interviewees for evaluating the accuracy of empirical findings.

\section{CASE ORGANISATIONS: LGA_NORTH AND LGA_EAST}


Since the aim of this paper is to validate the conceptual framework (Figure 2), the researchers focused on testing the influential factors (as discussed in Section 3). In doing so, two case studies were undertaken with this section reporting the data from them. Both case organisations are situated in England and are responsible for providing services throughout various sectors such as: social and environmental services, housing, education, health, etc. As reported earlier, structured, semistructured and unstructured interviews were conducted in both case organisations to investigate the decision-making process for electronic information sharing. These perceptions were seen from those stakeholders that were involved in the electronic information sharing process. From LGA_North, the stakeholders that were interviewed included the: Head of Information Technology (HIT), Project Manager (PM) and Information Services Manager (ISM). At LGA_East stakeholders interviewed included: Head of Information Communication and Technologies (HICT), Senior Information Systems Developer (SISD) and Information Service Delivery Manager (ISDM). Each interview from both the case organisations was interviewed based on structured, semi-structured and unstructured interviews. The reason for covering all the three forms of interview was to acquire as much detailed and accurate information from the interviewees as possible. Moreover, because the AHP technique was used in this research process to identify the prioritisation of EIS factors, there was a need to assure that the results received would be precise and meet the Consistency Ratio (CR) requirements of the AHP technique.

\section{Inter-Organisational Information Sharing and Integration Problems}

\section{LGA_North}

The interview sessions highlighted that LGA_North was faced with considerable pressures to cope with the extensive social regeneration of their borough, while trying to meet statutory requirements for integrated service delivery targets, performance indicators, e-Government targets, legislation changes and most importantly focusing on inter-organisational information sharing. In addition, LGA_North faced funding pressures and challenges in terms of improved resource and asset management. LGA_North was also confronted with a number of pressures. For example, to reduce the cost of maintaining non-integrated IT infrastructure, providing better service delivery, IT infrastructure and information integration, and support improved ways of working via collaboration, information sharing and remote/home working capabilities. The interviewees at LGA_North mutually agreed that:

"... their IT infrastructure was very much fragmented with different IS all over the borough with no integration and information sharing, there was no communication and lack of transparency and silo mentality prevailed ...".

LGA_North's efforts to modernise have been hindered by an IT infrastructure that has grown piecemeal over the years. LGA_North implemented various information systems to enhance their service delivery and share information internally and with other councils. These information systems did not solve all the problems as they used a variety of hardware of different ages, running different operating systems and software applications. Thus, LGA_North turned to integrated applications by developing manual point-to-point connections. However, such an approach has also led to a complex intertwining of applications, which increases the complexity of the integration solution as the number of interconnected applications rise thus, preventing in overcoming the limitations of their IT infrastructure and information sharing issues. These problems became an obstacle for LGA_North as they prevented it from implementing its business goals. For instance, LGA_North could not support its goal of closer collaboration, inter-organisational information sharing and coordination of interorganisational business processes due to the non-integrated nature of its applications. This also held LGA_North back from achieving cost reductions.

\section{LGA_East}

LGA_East is a big borough with several service areas. Each service area has its own IT infrastructure with numerous heterogeneous information systems that were based on a diversity of platforms, 
operating systems, data structures and computer languages. Most of these systems were legacy applications that still run today on mainframe environments. Since there was a lack of common IT infrastructure, and a lack of central coordination of IT, the majority of LGA_East departments adopted their own applications to support their business activities. These individual applications were not developed in a coordinated way but instead evolved as a result of the latest technological innovation. This led to incompatible systems with integration problems and most importantly no level of sharing of information internally as well as externally. LGA_East has attempted to overcome this problem by integrating their systems. For example, LGA_East implemented ERP systems to overcome their integration problems and automate their business processes. Although ERP systems partially addressed the problems of inter-organisational information sharing and integration, nevertheless, they simply provide some degree of solution for the integration problems. This is because ERP systems were not designed to integrate disparate systems but rather to replace them to achieve integration. The need for an integrated and flexible IT infrastructure has been necessitated with the existing infrastructure causing numerous problems. The interviewees at LGA_East illustrated that their IT infrastructure has been underdeveloped and not integrated and thus, several limitations existed, e.g. the interviewees mutually agreed that:

"... IT infrastructure was constructed in a departmental way. Each of the major service areas within this borough had their own IT infrastructure ... and this led to lack of information sharing and information integration".

\section{Electronic Information Sharing Process}

\section{LGA_North}

The limitations in the IT infrastructure led LGA_North to take a decision to significantly advance in electronic information sharing and service delivery by adopting a solution (e.g. making use of enterprise application integration technologies) to develop an integrated IT infrastructure. A project manager reported that:

"... the reasons for adopting the integration solution was reduction in duplication of data and cost of implementing an integrated IT infrastructure and improved information sharing, improvements in business process reengineering, savings and efficiency, streamlining processes, accuracy of data output and up-to-date information ...”.

LGA_North was faced with the option of withdrawing their heterogeneous systems and procuring new systems, or finding a method of migrating to a new generation of systems, which would support integrated service delivery. Due to the rich source of information contained in them and to make development more manageable, the second option was chosen to work on an integration project (covering IT infrastructure integration, information integration and integrated information sharing). The aim of the project was to provide citizens with better services and share information within and externally with other councils. Later during the interview sessions, the interviewees were asked to highlight the importance of factors influencing inter-organisational information sharing. The level of importance as presented in Table 1 follows a scale similar to the one used by Miles and Huberman (1994), i.e. scale of less important ( $\bigcirc)$, medium important (๑) and most important (○).

\section{INSERT TABLE 1 HERE}

As highlighted in Table 1, the factors have varied findings and such preferences on the importance of factors by the interviewees are simply based on the interviewee's observation, understanding and involvement during different inter-organisational information sharing projects within LGA_North. 


\section{LGA_East}

To overcome their integration problems, LGA_East initiated a plan for integrating their CRM system with their back-office legacy applications - focusing on a pilot project. The motivation behind this project was to address the limitations of its existing systems at a shorter scale, and to meet the targets set by the central government (i.e. later by working on large scale project based on the outcomes of this pilot project). The managing board made the decision for this project after discussing this issue with their project manager and other senior managers involved. The objective of this project was to demonstrate to LGA_East and to other LGAs that investing in a long-term programme of integration between CRM systems and legacy applications was necessary. On this basis the adoption of such integration architecture within LGA_East and other London boroughs would deliver measurable business benefit. Later during the interview sessions, the interviewees were also asked to highlight the importance of factors influencing electronic information sharing (Table 2). The level of importance as presented in Table 2 follows a similar scale as used for testing the factors used in Table 1.

\section{INSERT TABLE 2 HERE}

The results presented in Tables 1 and 2 may not seem sufficient as they are just based on the understanding and observation of the interviewees. Moreover, the analysis of the factors is confined to merely a set of three point scale of high, medium and low. It can be argued here that merely by discussing different factors and attaining the verbal results during the interview sessions, it may not be possible to identify the precise importance of each factor. Due to this reason and to enhance the research, the interviewees were asked to rank the factors based on their importance over other factors using a nine-point scale (Table 3). The importance of factors highlighted in Tables 1 and 2 for both the case organisations was based on the general discussions during the interviews. For example, during the initial discussions, the interviewees were asked "in your opinion do you think this factor is important (highly, medium or low) in the context of your organisation?" The authors perceived that this ranking of factors was not definite but helped in understanding an approximate value of each factor. However, to get a deeper insight and identify which factor is the most and least important, the AHP was utilised technique to test and assess the importance of factors. The use of AHP technique in developing a systematic decision-making process is discussed in the next section.

\section{INSERT TABLE 3 HERE}

\section{A Systematic Decision-Making Process for EIS Supported by AHP}

This section justifies the employability of the AHP technique to further prioritise the importance of factors influencing EIS. As the decision-making process for IS projects becomes more complex, several multivariate techniques have been developed to classify the importance of the influential factors. Determining the importance of the critical success/failure factors enables organisations to develop priorities when they plan to establish or improve their IS (Lam and Chin, 2005). Data Envelopment Analysis (DEA) can be considered as an example of multivariate techniques. DEA measures the efficiency rate by the ratio of a weighted sum of outputs over a weighted sum of inputs (Salmeron and Herrero, 2005). The weights or importance given to each of the criteria can take any value and none of them can be considered more important than any other. However, this method is more appropriate when the decision makers have no clear preferences on different factors, or when the interest is focused mainly on selecting the technology that performs better independent of any personal preferences (ibid).

Simple Multi Attribute Rating Technique (SMART) can also be selected to rank criteria that involve multi-criteria decision making (Dutta and Burgess, 2003; Edwards, 1977). The common procedure in this technique is to first identify the factor which is weighted most highly and second assess other criteria relative to that one (Belton, 1986). The assessment of this technique, as with DEA, illustrates that it does not incorporate the preferences structure of the decision makers, that is to report the perception of the decision makers about a single or number of factors. 
Additional techniques were also reviewed, for example the Ranking Approach (Buss, 1983) and Analytical Network Process (ANP) (Lee and Kim, 2000). However, the appropriateness and applicability of these techniques for the research presented in this paper is weakened since: (a) they involve quite complex mathematical models and extensive calculations, (b) most of the factors presented in this study are not quantifiable and (c) it is not easy for the managers in the public sector to fully understand the concept behind these approaches. In contrast, Analytical Hierarchy Process (AHP) allows decision makers to express their individual preferences (Salmeron and Herrero, 2005) and supports them not only by enabling them to model a complex problem and exercise judgement, but also by allowing them to incorporate both objective and subjective consideration in decisionmaking process (Forman and Selly, 2001).

AHP allows decision-makers to express their individual preferences (Kamal and Alsudairi, 2009; Saaty, 1980). Therefore, EIS factors may be prioritised using the set of decision-makers' preferences to get a score and this can provide a ranking of EIS factors for each decision-maker. Each decision maker can decide (according to his/her preferences) that a specific EIS factor is more important over other factors. The AHP technique has the advantage of a detailed stepwise comparison mechanism over other techniques, i.e. the ability to check for and to reduce any inconsistency scores there and then, and also the opportunity in one exercise to obtain decision-makers concerning prioritisation (Saaty, 1980). AHP has been used to reflect the importance, or weights, of the factors associated to priorities (Zahedi, 1986) and it has been widely applied in the field of IS (Khoo et al., 2002). However, there is no literature evidence on prioritising the importance of EIS factors in LGAs - with the exception of [withheld for blind review], who prioritised the importance of factors influencing enterprise application integration adoption in LGAs. The rationale for choosing AHP, despite the controversy of its rigidity, is that this technique is well suited for decision-making and offers numerous benefits as a synthesizing mechanism. AHP encompasses four basic steps: decomposition (i.e. constructing the hierarchy model), comparative judgments (i.e. pairwise comparison), and synthesis of priorities (i.e. determining normalised priority weights and analysing and calculating the priority weights).

- Constructing the Hierarchy Model: In order to study EIS related factors in LGA_North and LGA_East, five categories of factor layers were established: Business Process, Benefit/Barrier/Risk (BBR), Environmental, Organisational and Technological. Identifying the degree of importance associated with the factors can be resolved by decomposing it into sub-problems within a hierarchy structure. The highest level in the hierarchy is the goal (Level 1: Goal - EIS in LGAs) to reach, Level 2 illustrates the categories of factor layers and the elements in the lowest level are the factors (Level 3: Factors Influencing EIS in LGAs). The goal here is to obtain users' perceptions about the importance of factors in order to establish a rank among them. It is a valuable effort, since IS users and experts have significantly different perceptions of IS success (Jiang et al., 2002). Once the factors are chosen with a defined hierarchy among them, the following step is focused on collecting data by pairwise comparisons of the different criteria.

- Pairwise Comparison: Making pairwise comparisons is a more reliable way of obtaining the actual weights than obtaining them directly as it is generally easier to evaluate the relative weights of each factor with respect to the others [withheld for blind review]. However, before performing the pairwise comparisons, all the interviewees were given instructions on how to conduct the comparison among the factors. The judgment of the importance of one alternative over another can be made subjectively and converted to a numerical value using a scale illustrated in Table 3. The numerical values representing the judgments of the comparisons are arranged in a matrix for further calculations. The comparison is made among the factors with respect to the factor categories. All the pairwise comparison results were recorded on a sheet of paper, which was used later for discussion with the interviewees. The comparison process for the entire decision hierarchy took 30-45 minutes to complete, intervened with a 
few questions in the process. After that, the interviewees started to discuss their responses to the AHP tables, trying to achieve an agreement among their evaluations. After each round of discussion, the interviewees were allowed to revise their evaluations to better reflect their perception and understanding on the issues (keeping in view to have a Consistency Ratio less than or equal to 0.01 , as any data that was beyond 0.01 was considered invalid). In the meeting, although interviewees had difficulties getting consensus on several judgments, sufficient agreement emerged to permit the averaging of results.

- Determine Normalised Priority Weights: The third step is to determine the normalised priority weights and local weights of all the factors using Expert Choice (EC) software. EC is designed for the analysis, synthesis and validation of complex individual or group decisions. It assists with the decision-making processes by providing decision-makers with a structure to organise and evaluate the importance of various objectives.

- Analysing and Calculating the Priority Weights: Based on normalised priority weights from all the interviewees from both case organisations, the relative priority importance of EIS factors are analysed and calculated in Tables 4 and 5. These priority weights are obtained by using the EC software and the conclusions drawn from them are the final results of the analysis of collective judgements provided by the panel of interviewees selected from LGA_North and LGA_East. For example, in Table 4 (similar discussions follow for Table 5 with a comparison of Tables 4 and 5 presented in Table 6) in the Business Process Factor Category, work process factor is considered as the most important factor with a 0.6666 (1) global weight, whereas, decision process is the least important factor in this category with a 0.3333 (2) global weight. The global weights are calculated by taking the average of all the priority weights of each interviewee. Similarly, in the BBR Category, perceived benefits is the most important factor with 0.5950 (1) global weight, whereas, perceived risks has the least importance with 0.1080 (3) global weight. The results presented in Table 4 and 5 do not signify that any factor is unimportant or least important. It actually exhibits the interviewees' perceptions about the importance of EIS related factors in more detail. This process of identifying the importance of factors may assist the LGA_North and LGA_East decisionmakers in comprehending the significance of EIS in the local government context.

\section{INSERT TABLE 4 HERE}

INSERT TABLE 5 HERE

\section{DISCUSSIONS AND SYNTHESIS OF THE RESULTS}

The objectives of this paper are to investigate and empirically validate the factors influencing participation in inter-organisational EIS (by utilising the AHP technique) at a local governmental level. As noted from the results, different stakeholders (i.e. the interviewees) from both the case organisations have diverse views on the prioritisation of EIS related factors. If seen individually, for the eighteen factors all the interviewees provided relatively different rankings. This can be attributed to their understanding and involvement in EIS within LGA_North and LGA_East, respectively. Almost all of the factors gathered through reviewing relevant literature emerged from the case studies and can be discussed accordingly based on their context.

\section{Environment Layer}

According to Tables 1 and 2, the interviewees identified the four environmental factors as either most important or of medium importance in influencing participation in EIS. The senior managers in the LGAs clarified that political and economic pressure from the central government can play a significant role in persuading the LGAs to adopt and participate in EIS among and within themselves. The case studies showed that Central government encourages the local councils to share information electronically by improving their IT capability and providing the necessary training for employees. Moreover, Central government has defined a legal policy called "Information Sharing Protocol" 
which is an overarching framework for sharing information in LGAs. The interviewees clarified this framework as an important guidance in order to define the legal background on EIS, and outline the principle which needs to be carried out within and among LGAs. In addition, the case studies showed that the LGAs were affected by the action of other local authorities while they were making their decisions on whether to share information electronically or not. For instance, the project team in LGA_East initially investigated and analysed the solutions of other boroughs and how these benefited them. Based on the importance of the factors in this layer (summarised in Table 6), economic issues and pressure have been ranked as the main influential factor in both LGAs. This is due to the budget deficit faced by local authorities in which they must reduce the level of spending on any projects. Central government tries to reduce the operational costs by encouraging local agencies to establish network collaborations among different departments to be able to share their services, processes, and information, however, these initiatives have not been operationalised yet. On the other hand, as Central government sets out plans for a significant acceleration in the reduction of current budget deficit, the budget of LGAs has been reduced by more than $7 \%$ a year in real terms, which represents the biggest budget cut in the entire public sector. As a result, local councils are under enormous pressure to double their efforts to find efficiency in the way they deliver services towards citizens or face the prospect of cutting the services themselves.

\section{Organisational Layer}

The interviewees ranked almost all of the organisational factors as the most important factors influencing EIS participation in LGAs. They argued that sharing some sensitive information requires permission by top ICT management within the authority. Therefore, knowledge, commitment and capability of top management are the key drivers to push the agency to participate in EIS. Since local authorities were faced with some essential barriers to share the information electronically in large scale, central government published the "Information Sharing Vision Statement" in 2006. This was part of the Service Transformation Plan, a cross-organisation programme with the aim of overcoming barriers within the public sector. However, this vision statement has a broad approach to EIS initiative. The gathered data shows the requirements regarding participation in EIS vary from one LGA to another; hence contribution in EIS based on the vision becomes a complex task. The respondents highlighted the importance of network collaboration and trust by ranking them as the most important factors influencing EIS participation. It can be observed from the cases that working in a networked environment become problematic within and among LGAs. Some departments in local authorities deal with sensitive information (e.g., citizen health records) and therefore, they are hesitant to trust other departments and share the information. On the other hand, financial capability was one of the most cited factors influencing EIS by the interviewees. This factor should be taken into consideration cautiously as Central government will cut the total budget of the local authorities. This means LGAs will, inevitably, focus on more vital objectives rather than spending money on EIS initiative. Based on prioritisation of factors in this category, the results from each LGA are slightly different. In LGA_North financial matters ranked as the most important factor, while in LGA_East it was management capability. However, it can be perceived that both LGAs are concerned about the same thing; "how much should we spend on given project". The management team in LGA_East believed that it is the top-level people's responsibility to handle this challenging situation when there are uncertainties over the allocation of the reduced budget. On the other hand, Goals and Objectives in LGA_North, and Network Collaboration in LGA_East received the least weight. It can be interpreted that formation of network collaboration among different agencies in local authorities is a fairly new concept which was not officially defined in their goals and objectives, hence receiving less attention in the ranking.

\section{Business Process Layer}

Adopting new technology in any organisation requires a certain level of compatibility with existing work and decision processes. Interviewees in both LGAs stressed that an essential change is required in their work processes and operating procedures in order to be able to share information electronically. The interviewee in LGA_East raised the concern that information sharing cannot save money and improve performance in their organisation as the decision and business processes are not 
aligned among different department. They argued that change in work and decision processes become vital when a local authority uses and makes decisions based on the information that has been gathered by another agency. In an environment like local government authorities where each department has individualised business rules and policies which dictate how the decision should be made and the work should be done, collaboration and cooperation become unmanageable. Prioritisation of the factors demonstrates that work processes received more attention regarding participation in EIS. Besides technological integration, harmony in the operational processes of participating agencies has been identified as an essential issue influencing EIS. This concern arises by both LGAs because in the hierarchical bureaucratic structure of public agencies business processes and functions are often difficult to change. Based on the prioritisation of factors in this layer (Table 6), work process received the highest rank in both LGA_North and LGA_East. The interviewees in both authorities clarified that redesigning current business processes is inevitable.

\section{Technology Layer}

The interviewees recognised the four technological factors - IT Capability, Data Quality, Data Standard and Data Security as highly important issues influencing the authority's decision to share information electronically. Regarding the IT capability issues, the Head of IT in LGA_North, for instance, stated that different departments within the council deployed different IT networks and implemented various information systems with different standards and platforms where sharing information became a major problem. This illustrates that there is no cohesion between various departmental and corporate systems and an almost complete lack of integration with delivery services and information systems. Similarly, the interviewees in LGA_East discussed that there are several limitations to share information electronically as their IT systems are not sufficiently capable. Also, they were concerned about data quality as there is a redundancy and duplication of data and functionality in which different departments gather and store data in different ways. The interviews, in addition, illustrate that data security and privacy is certainly an important issue because citizens' data is very confidential and citizens will not want the borough and its staff to misuse their personal information. Technological capability has been recognised as the most influential factor on EIS by LGAs. The interviewees ranked this factor as the highest because it would encompass the department IT Infrastructure, IT sophistication and also Staff IT knowledge which are the concrete for information sharing effort. Inter-agency information systems (i.e. ERP systems) are complicated systems which integrate number of databases, hardware and telecommunication technologies. Thus, participating in such systems requires a certain level of IT infrastructure. However, lack of sufficient IT foundation in local governments has been identified as an obstruction to inter-agency collaboration initiatives. On the other hand, data standards have been given the least weight due to a lack of attention to such an initiative in LGAs. It is worth mentioning that there is a lack of emphasis on how participating agencies should agree on integrating heterogeneous applications based on the structure or language of the messages exchanged. Based on prioritisation of factors in this category (Table 6), IT Capability and Data Quality ranked as the most important factors influencing EIS. The major concern in both authorities was that how to define compatibility standards to be adopted among information systems implemented in the organisation. The lack of standards leads to the absence of interoperation among the cooperate systems in both LGAs. Therefore, when the systems and organisations are not able to interoperate then information cannot be accepted and shared among them. Moreover, building a common perspective towards information quality in inter-agency collaboration becomes a complicated task as the wants and needs of participating agencies are dissimilar.

\section{Barrier/Benefit/Risk Layer}

The interviewees highlighted the influential role of benefits, barriers, and risk of sharing information electronically. During the interviews in LGA_East the candidates argued that identifying potential benefits of inter-agency information sharing in public sector could play an important role in encouraging participation in this initiative. They explained that in local authorities there is an unreal expectation of the project outcome and impatience in gaining benefits in the early stages of the projects. These situations can severely limit the expectation of information sharing benefits and might 
result in failure of the project. Although several benefits can be gained through participating in EIS, they should be identified and set based on the organisation resources to keep the expectations real. Although any organisation recognises and analyses the perceived risks associated with interagency information sharing, the interviewees in LGA_North did not identify this as a significant factor. A wrong perception among local authorities becomes a norm that by employing private sector providers to develop and maintain their information technology, the risk of the projects would be directed to the third party as well. This outsourcing would cause several risks such as lack of full control on personal information, using different providers within the organisations which make integrity much more complex, etc. Similar results are gathered through the prioritisation of factors in which perceived risk received the least weight by LGA_North while it is placed as the second influential factor by LGA_East. On the other hand, perceived benefits ranked on the top by both organisation. It can be interpreted that the organisations assess the benefits of information sharing, but not the risk regarding the effort.

There is less literature that specifically discusses on the importance of these factors in the manner presented in this paper. Despite, this assertion these factors have been reported to impact top management in private and public (including government) organisations in influencing their decisionmaking process. This concludes that although these factors are reported as vital, nonetheless, there is a lack of a systematic process that specifically prioritises these factors (as illustrated in this paper). The authors argue that the concept of "prioritising the importance of factors influencing EIS in $L G A s$ " presented in this paper makes a novel contribution both at the conceptual and empirical level. As highlighted in Tables 8 and 9, it is quite instinctive that each individual presents different views on the importance of the factors. Nevertheless, the views of all individuals should be considered, rather than a single one. Similar to the integration issues in LGAs, information sharing is also an inescapable dilemma for LGAs and other government agencies for successful service delivery provisions, which requires the devotion of each stakeholder (i.e. interviewees), involved in EIS. Therefore, it is indispensable to take the views of all stakeholders into account in the prioritisation of factors. However, the essence in using this technique is that it has the ability of determining the priorities of factors as shown in Tables 8 and 9, thus allowing the researchers and practitioners in LGAs in determining which EIS factor must be first given attention. EIS is no longer just an option but a necessity for LGAs aiming for better service delivery and operational efficiency. Relevant strategies and organisational-wide policies play the primary role in making EIS a success. The application of AHP technique in prioritising EIS factors explained in this paper provides a direction for consideration of the evaluation of LGA strategies towards their EIS practices. Both the case organisations offer an illustrative reference for such evaluation, as also highlighted in Table 6 (a comparison of both the case organisations in relation to their prioritisation results). Therefore, the analysis presented in this paper would be beneficial for evaluating any other LGA EIS practices while also prioritising its influential factors.

\section{INSERT TABLE 6 HERE}

\section{LESSONS LEARNT FROM THE CASE ORGANISATIONS}

Through the empirical findings presented earlier, the area of electronic inter-organisational information sharing in LGA_North and LGA_East was studied by testing the factors. No claim for generalisation is made for interpretive research of this type. It is not the intention of this paper to offer prescriptive guidelines for EIS in LGAs, but rather to describe case organisation perspectives that allow others to relate their experiences to those reported. The factors influencing EIS which were identified through reviewing the literature and justify through conducting case studies are independent but interconnected. This means different layers of the conceptual framework (Figure 3) have an effect on each other and it highlights the socio-technical nature of electronic information sharing. Also, the results in the form of importance of factors (Tables 1 and 2), illustrate that the conceptual framework is well accepted within the two case organisations. The data collected from the 
two case organisations was confirmed to be of relatively similar significance with marginal differences - thus increasing the validity of the conceptual framework.

This paper offers a broader understanding of the phenomenon of EIS in LGAs. Therefore, what we learnt from the case studies conducted is a result of the description provided and do not seek to be prescriptive. These lessons might be helpful to LGAs as well as researchers and IT practitioners and are summarised as follow:

- Lesson 1: The role of Central Government; the empirical findings confirmed that the central government has a key role to encourage and persuade LGAs to participate in EIS within and among local authorities by providing them with suitable funding, improve their IT infrastructure and enhance the level of IT skills and knowledge among the employees.

- Lesson 2: The necessity of having a strong leadership on Board; the findings illustrate that in this challenging time when public sector organisations are forced to reduce their costs, strong leadership is needed to realise the change and to build inter-agency collaboration among the authorities.

- Lesson 3: The need for infrastructure re-engineering; the empirical data show that corporate applications are currently disintegrated and information is duplicated among databases which make information sharing impossible. Specific organisational change is required to implement new ICT-enabled and service-led business processes that cross traditional organisation boundaries where information can securely and efficiently be shared between departments.

- Lesson 4: The need for professionalism in information management: another important lesson learnt from the case organisations is that most managers do not recognise the value of information or appreciate the importance of its quality. Failure to share information within and across local government agencies is widespread, and the attention to privacy and security of citizens' data is imperfect. Therefore there is a need for professionals to address these issues since the more LGAs protect the sensitive information, the less they will be criticised by the public.

Hitherto, the authors presented the prioritisation of factors as a contribution and research novelty in this paper. However, in a wider context the key beneficiaries are the decision makers, top management and practitioners within LGAs, as well as researchers within the academic community. All of these parties benefit from the research in this paper as a guideline to analyse and understand EIS in LGAs. In doing so, this work contributes to the body of knowledge and practice in the areas of EIS and LGAs by providing sufficient support to the decision makers in speeding up the process of EIS in LGAs.

\section{CONCLUSION AND IMPLICATIONS}

The main strength of this paper is that it provides a technique for prioritising the importance of factors influencing EIS in both the case organisations. The authors through this paper support their argument that the concept of prioritising the importance of factors can be further applied in other cases across the UK and EU region, in order to gain better understanding of factors influencing EIS in the local government context. The technique seems to perform better than results based purely on the experts' assignation of the absolute priorities of each factor or than results based just on qualitative analysis. Note also that, by using this technique, the importance of each factor is compared to the others. According to experts, the fact of seeing factors relative to others (i.e. making comparisons) seems to be an easier way to calibrate their importance. Furthermore, by using AHP, some inconsistencies may arise, giving place for reconsideration of judgements and unveiling some unclear thinking regarding the assessments of some of the factors. However, this technique has not traditionally been applied for 
the analysis of factors related with EIS in LGAs. Thus, we suggested that it is mostly appropriate to use this technique while pursing similar research studies. However, usage of AHP is not limited to the extent as applied and explained in this research; it can be applied to a wide range of decision-making problems with multi-attributes and alternatives. Although, the result may differ according to the viewpoint (since decisions are subjective by their nature) mechanism of the technique is the same. In addition, the results do not mean that any factor is unimportant. It means what are the interviewees' perceptions about the importance of them. This is a main issue, since it is possible to manage the development process with more information about the expectations of final users. This work is focused on the users' point of view. This is a useful technique since users' satisfaction may be more critical in EIS. This technique tests the factors through two case studies. The weights for different factors obtained by using the AHP technique can be subsequently used to prioritise the importance of EIS in LGAs.

The combination of theoretical discussions, analysis of the literature and empirical research discussed earlier represents the start of research on EIS participation in LGAs especially in the UK. Participating in inter-organisational electronic information sharing and integration is a challenging issue in LGAs as it requires understanding of LGA business processes and reengineering the organisational structures in some cases. LGAs have recognised that they can gain significant advantages by sharing and integrating their information electronically. As discussed in Section 3, EIS phenomena should be seen as a socio-technical issue in which a range of environmental, organisational, and technological factors would affect the outcome. Therefore, this paper attempts to identify and analyse the factors which influence participation in EIS projects by suggesting a conceptual framework. Empirical data for this study were collected through various sources of data such as structured and semi-structured interviews, governmental documentations and observations from the case organisations in order to validate the factors influencing the participation in EIS within LGAs. As depicted in the empirical findings, all the factors were validated throughout the case studies (though with different prioritisation results), thus, supporting the authors' proposed conceptual framework.

\section{Limitations and Future Recommendation}

The result of this research cannot be generalised and should be developed further. One reason of this limitation is because of the organisational structure of LGAs in the UK. There are five different types of local authorities in the UK which are divided into single-tier and two-tier authorities with differences in structure, nature, size, etc. Accordingly, it is recommended to conduct a large-scale survey regarding EIS participation in LGAs in order to be able to prioritise the influential factors and provide a guideline to the authorities to improve this initiative.

\section{REFERENCES}

Agranoff, R. and McGuire, M. (2001) Big questions in public network management research. Journal of Public Administration Research and Theory, 11(3), 295.

Akbulut, A. Y., Kelle, P., Pawlowski, S. D. and Schneider, H. (2009) To share or not to share? Examining the factors influencing local agency electronic information sharing. International Journal of Business Information Systems, 4(2), 143-172.

Anderson, J. C. and Narus, J. A. (1986) Toward a better understanding of distribution channel working relationships. In K. Backhaus, and D. Wilson (Eds.), Industrial marketing: A german-american perspective (pp. 320-336). Berlin: Springer Verlag.

Beaumaster, S. (2002) Local government IT implementation issues: A challenge for public administration. System Sciences, 2002. HICSS. Proceedings of the 35th Annual Hawaii International Conference on, 17251734.

Belton, V. (1986) "A comparison of the analytic hierarchy process and a simple multi-attribute value function", European Journal of Operational Research, vol. 26, no. 1, pp. 7-21.

Buss, M.D. (1983) "How to rank computer projects", Harvard business review, vol. 61, no. 1, pp. 118-125.

Cavaye, A. L. M. (1996) "Case study research: a multifacted research approach for IS", Information Systems Journal, Vol. 6, No. 3, pp. 227-242. 
Clegg, C., Axtell, C., Damodaran, L., Farbey, B., Hull, R. and Lloyd-Jones, R. (1997) Information technology: A study of performance and the role of human and organizational factors. Ergonomics, 40(9), 851-871.

Dawes, S. S. (1996) Interagency information sharing: Expected benefits, manageable risks. Journal of Policy Analysis and Management, 15(3), 377-394.

Denzin, N. Y. K. and Lincoln, Y. (1994) "Handbook of Qualitative Research", SAGE Publications, London, UK.

Doherty, N. F. and King, M. (2005) From technical to socio-technical change:Tackling the human and organizational aspects of systems development projects.14, 1-5.

Dutta, R. and Burgess, T. (2003) "Prioritising information systems projects in higher education", Campus-Wide Information Systems, vol. 20, no. 4, pp. 152-158.

Edwards, W. (1977) "How to use multiattribute utility measurement for social decisionmaking", Systems, Man and Cybernetics, IEEE Transactions on, vol. 7, no. 5, pp. 326-340.

Faerman, S. R., McCaffrey, D. P. and Van-Slyke, D. M. (2001) Understanding interorganizational cooperation: Public-private collaboration in regulating financial market innovation. Organization Science, 12(3), 372388.

Fan, J. and Zhang, P. (2007) A conceptual model for G2G information sharing in E-government environment. 6 Th Wuhan International Conference on E-Busines.

Forman, E.H. and Selly, M.A. (2001) Decision by objectives: how to convince others that you are right, World Scientific Pub Co Inc.

Fountain, J. (2001) Public Sector: Early Stage of a Deep Transformation. The Economic Payoff from the Internet Revolution, edited by the Brookings Task Force on the Internet,Washington DC: Brookings Institution ,235-268.

Gil-Garcia, J, R., Guler, A., Pardo, T. A. and Burke, G. B. (2010) Trust in government cross-boundary information sharing initiatives: Identifying the determinants. Hicss, 1-10.

Gil-Garcia, J. R., Pardo, T. A. and Burke, G. B. (2007a) Government leadership in multi-sector IT-enabled networks: Lessons from the response to the west nile virus outbreak. Workshop 4: Leading in a MultiSector Environment,

Gil-Garcia, J. R., Smith, C. and Duchessi, P. (2007b) Collaborative e-Government: impediments and beneftis of information-sharing projects in the public sector. European Journal of Information Systems 16, 121-133

Guo, Z., Fang, F. and Whinston, A. B. (2006) Supply chain information sharing in a macro prediction market. Decision Support Systems, 42(3), 1944-1958.

Irani, Z., Ezingeard, N. and Race, P. (1999) "A case study strategy as part of an Information systems research methodology: A critique”, International Journal of Computer Applications in Technology, Vol. 12, No. 2/5, pp. 190-197.

Jankowicz, A. D. (2000) Business Research Project. Business Press, London.

Heeks, R. B. (2006) Implementing and managing eGovernment. London, UK: Sage.

Irani, Z. (1998) Investment Justification of Information Systems: A Focus on the Evaluation of MRPII. PhD Thesis, Department of Manufacturing and Engineering, Brunel University, London, UK.

Jiang, J. J., Klein, G. and Discenza, R. (2002) "Perception differences of software success: provider and user views of system metrics”, Journal of Systems and Software, Vol. 63, No. 1, pp. 17-27.

Kamal, M. M, Hackney, R. and Ali, M. (2012) "Facilitating Enterprise Application Integration Adoption: An Empirical Analysis of UK Local Government Authorities", International Journal of Information Management, In Press.

Kamal, M. M. and Alsudairi, M. (2009) "Investigating the Importance of Factors Influencing integration technology adoption in local government authorities", Transforming Government: People, Process and Policy, 3 (3), 302-331.

Kelle, P. and Akbulut, A. (2005) The role of ERP tools in supply chain information sharing, cooperation, and cost optimization. International Journal of Production Economics, 93, 41-52.

Kim, H. J. and Bretschneider, S. (2004) Local government information technology capacity: An exploratory theory.

Khoo, L. P., Chen, C. and Yan, W. (2002) "An investigation on a prototype customer-oriented information system for product concept development”, Computers in Industry, Vol. 49, No. 2, pp.157-174.

Lam, P.K. and Chin, K.S. (2005) "Identifying and prioritizing critical success factors for conflict management in collaborative new product development", Industrial Marketing Management, vol. 34, no. 8, pp. 761-772.

Lam, W. (2005) Barriers to e-government integration. Journal of Enterprise Information Management, 18(5), 511-530.

Landsbergen, Jr. D. and Wolken, Jr. G. (2001) Realizing the promise: Government information systems and the fourth generation of information technology. Public Administration Review, 61(2), 206-220. 
Lee, J. K. and Rao, H. R. (2007) Exploring the causes and effects of inter-agency information sharing systems adoption in the anti/counter-terrorism and disaster management domains. Proceedings of the 8th Annual International Conference on Digital Government Research: Bridging Disciplines \& Domains, 163.

Lee, J.W. and Kim, S.H. (2000) "Using analytic network process and goal programming for interdependent information system project selection", Computers \& Operations Research, vol. 27, no. 4, pp. 367-382.

Lou, H., Luo, W. and Strong, D. (2000) Perceived critical mass effect on groupware acceptance. European Journal of Information Systems, 9(2), 91-103.

Luna-Reyes, L. F., Zhang, J., Gil-Garcia, J. R. and Cresswell, A. M. (2005) Information systems development as emergent socio-technical change: a practice approach. European Journal of Information Systems 14, 93105 .

Miles, M. and Huberman, A. (1994) Qualitative Data Analysis: An Expanded Sourcebook, Sage, Newbury Park, California.

Navarrete, C., Gil-Garcia, J. R., Mellouli, S., Pardo, T. A. and Scholl, J. (2010) Multinational E-government collaboration, information sharing and interoperability: An integrated model.

Neergaard, H. and Ulhoi, J. P. (2006) Government agency and trust in the formation and transformation of interorganizational entrepreneurial networks. Entrepreneurship Theory and Practice, 30(4), 519-539.

Pardo, T. A., Gil-Garcia, J. R., Burke, G. B. (2006) Building response capacity through cross-boundary information sharing: The critical role of trust. Exploiting the Knowledge Economy: Issues, Applications, Case Studies.

Pardo, T. A. and Tayi, G. K. (2007) Interorganizational information integration: A key enabler for digital government., 691-715.

Philip, G. and Pedersen, P. (1997) "Inter-Organizational Information Systems: Are Organizations in Ireland Deriving Strategic Benefits from EDI?, International Journal of Information Management, Vol. 17, pp. 337 $-357$

Remenyi, D. and Williams, B. (1996) "The nature of research: qualitative or quantitative, narrative or pragmatic?", Journal of Information Systems, Vol. 6, pp. 131-146.

Rogers, E. M. (1983) Diffusion of innovations Free Pr.

Rogers, E. M. (1995) Diffusion of innovations Free Pr.

Saaty, T. L. (1980) "The Analytic Hierarchy Process: Planning, Priority Setting: Resource Allocation", McGraw-Hill, New York.

Salmeron, J. L. and Herrero I (2005) "An AHP-based methodology to rank critical success factors of executive information systems", Computer Standards \& Interfaces, Vol. 28, pp. 1-12.]

Saunders, M., Lewis, P. and Thornhill, A. (2000) "Research Methods for Business Students," Essex, Pearson Education Ltd.

Scholl, H. J. J. and Klischewski, R. (2007) E-government integration and interoperability: Framing the research agenda. International Journal of Public Administration, 30(8), 889-920.

Schutz, A. (1967) "The phenomenology of the social world", Evanston, IL: Northwestern University Press.

Senyucel, Z. (2005) Towards successful E-government facilitation in UK local authorities. Proceedings of the eGovernment Workshop, , 5

Tan, C. W. and Pan, S. L. (2003) Managing e-transformation in the public sector: an e-government study of the Inland Revenue Authority of Singapore (IRAS). European Journal of Information Systems 12, 269-281.

Themistocleous, M., Irani, Z., Kuljis, J. and Love, P. (2004) Extending the information system lifecycle through enterprise application integration: A case study experience. System Sciences, 2004. Proceedings of the 37th Annual Hawaii International Conference on, 8.

Yin, R. K. (1994) "Case Study Research Design and Methods", Sage, London.

Zahedi, F. (1986) "The analytic hierarchy process. A survey of the method and its applications", Interfaces, Vol. 16, No. 4, pp. 96-108.

Zaheer, A., McEvily, B. and Perrone, V. (1997) 'Does trust matter? Exploring the effects of interorganizational and interpersonal trust on performance', Organizational Science, forthcoming.

Zheng, L., Dawes, S. and Pardo, T. A. (2009) Leadership behaviors in cross-boundary information sharing and integration: Comparing the US and china. Proceedings of the 3rd International Conference on Theory and Practice of Electronic Governance, 43-50. 


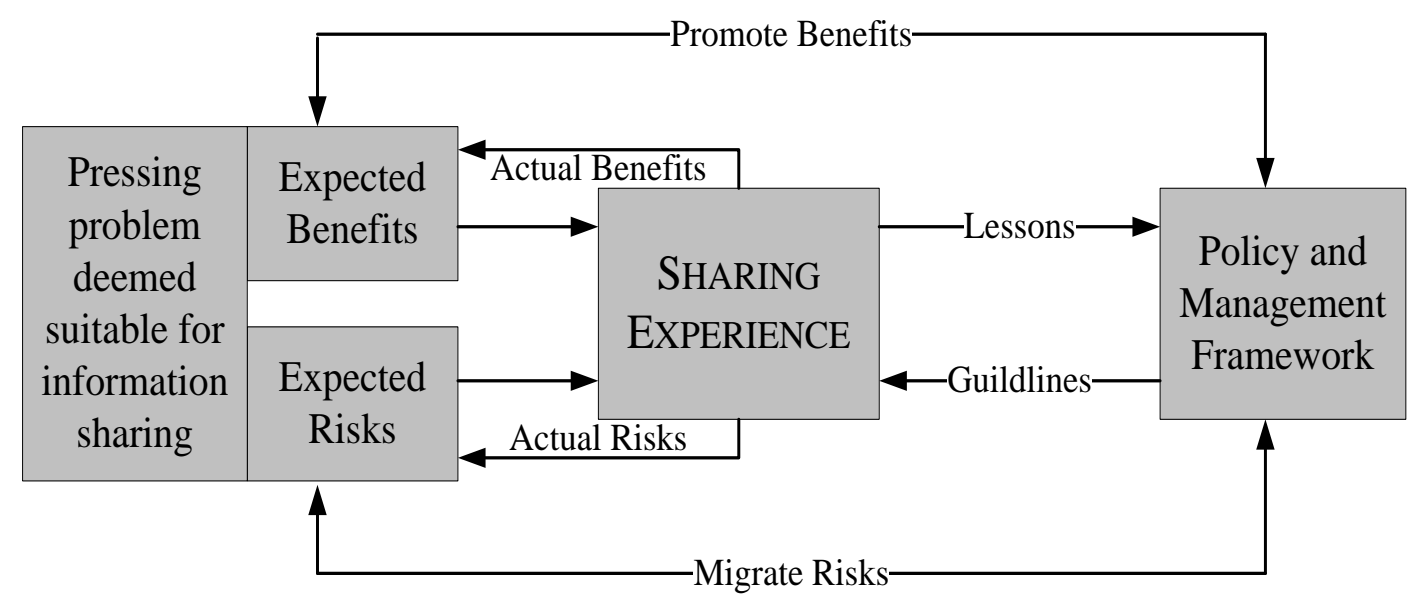

Figure 1: Theoretical Model of Interagency Information Sharing (Source: Dawes, 1996)

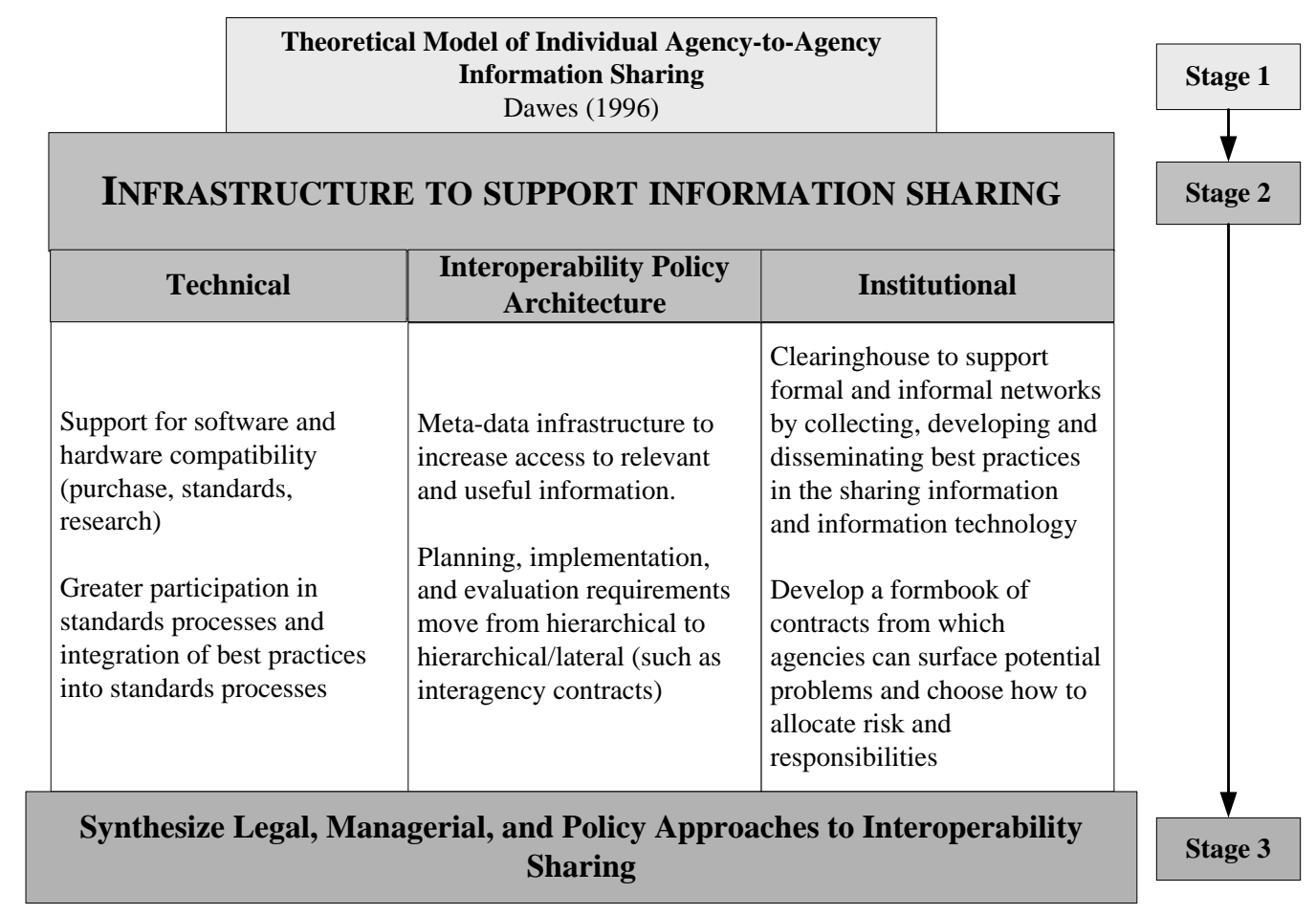

Figure 2: Extended Theoretical Model of Interagency Information Sharing (Source: Landsbergen and Wolken, 2001) 


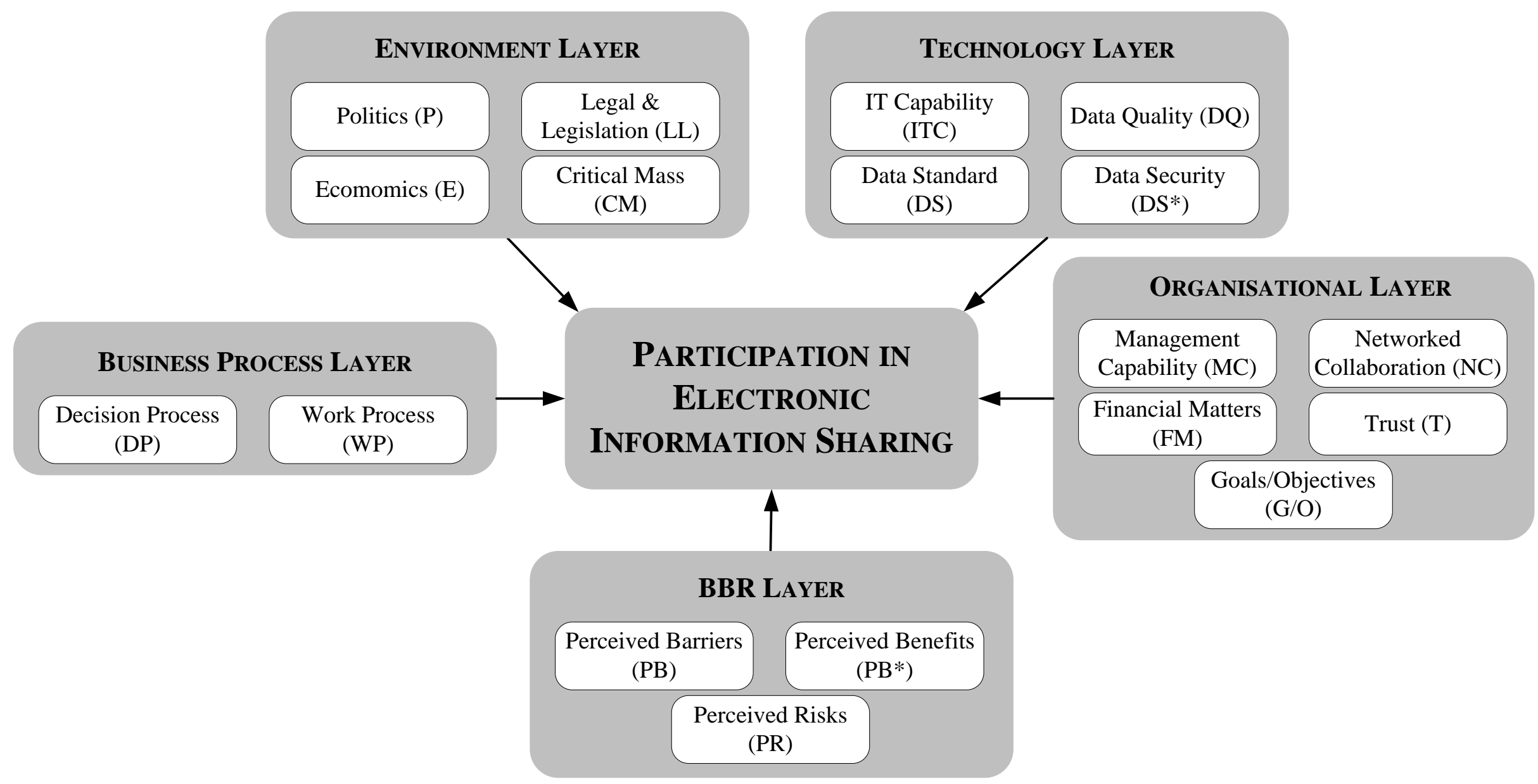

Figure 3: Proposed Conceptual Framework of Factors Influencing Inter-Organisational Electronic Information Sharing and Integration 


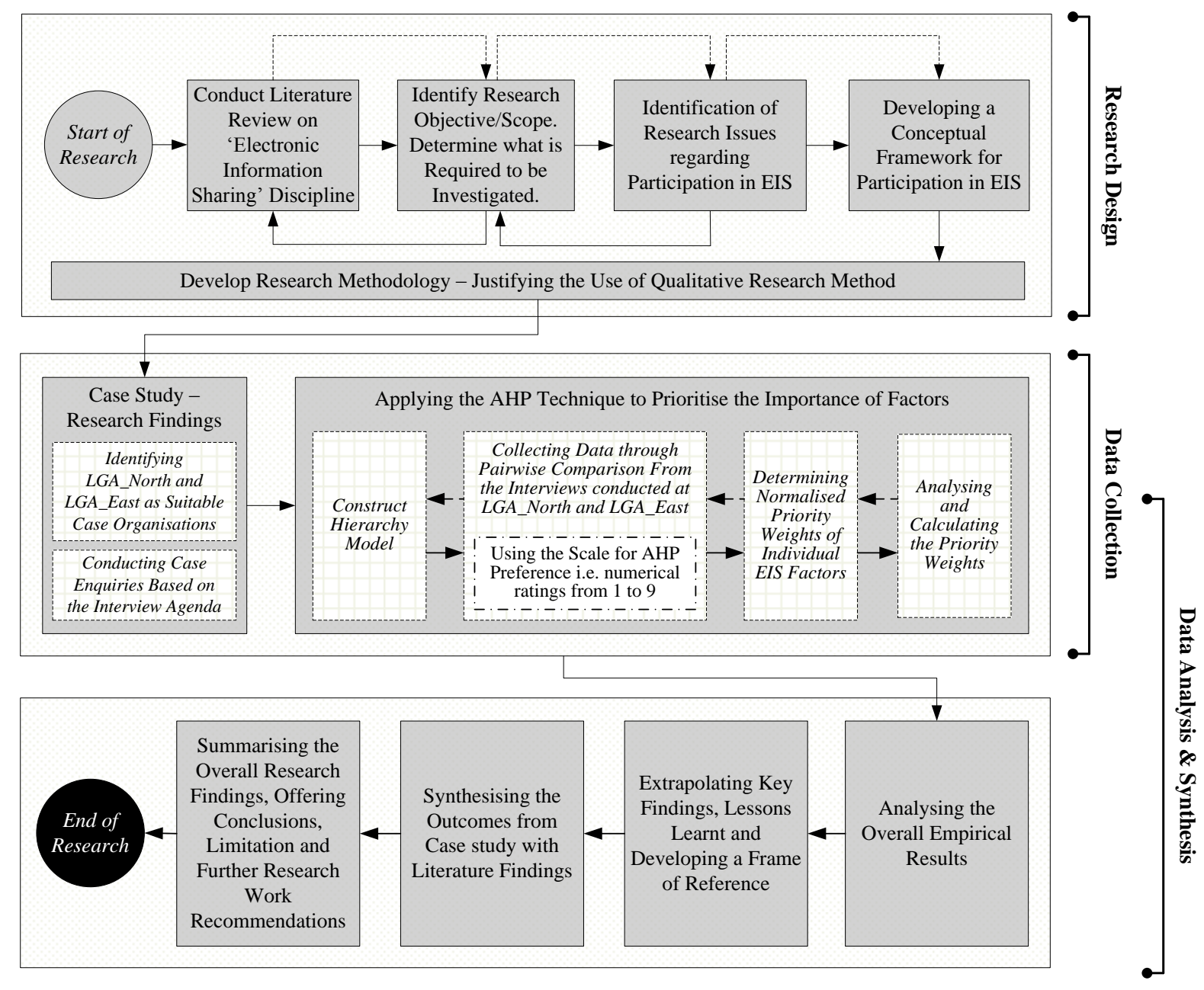

Figure 4: Empirical Research Framework

\begin{tabular}{|c|c|c|c|c|}
\hline & \multirow[b]{2}{*}{ Factors } & \multicolumn{3}{|c|}{ LGA_North } \\
\hline & & HIT & PM & ISM \\
\hline \multirow{2}{*}{$\frac{5}{2}$} & Work Process & 0 & 0 & O \\
\hline & Decision Process & 0 & 0 & $\bigcirc$ \\
\hline \multirow{3}{*}{ 先 } & Perceived Benefits & 0 & 0 & 0 \\
\hline & Perceived Barriers & O & 0 & 0 \\
\hline & Perceived Risks & $\bigcirc$ & $\bigcirc$ & O \\
\hline \multirow{4}{*}{ 壱 } & Politics & 0 & 0 & O \\
\hline & Economics & 0 & 0 & 0 \\
\hline & Legal \& Legislation & O & O & O \\
\hline & Critical Mass & 0 & O & ○ \\
\hline \multirow{5}{*}{$\frac{5}{0}$} & Managerial Capability & 0 & 0 & 0 \\
\hline & Mutual Goals/Objectives & 0 & 0 & ○ \\
\hline & Networked Collaboration & 0 & O & 0 \\
\hline & Trust & 0 & 0 & O \\
\hline & Financial Matters & 0 & 0 & 0 \\
\hline \multirow{4}{*}{ 空 } & IT Capability & 0 & 0 & 0 \\
\hline & Data Quality & 0 & 0 & 0 \\
\hline & Data Standard & 0 & 0 & 0 \\
\hline & Data Security & 0 & 0 & 0 \\
\hline
\end{tabular}

Table 1: Importance of Factors Influencing EIS at LGA_North 


\begin{tabular}{|c|c|c|c|c|}
\hline & \multirow[b]{2}{*}{ Factors } & \multicolumn{3}{|c|}{ LGA_East } \\
\hline & & HICT & SISD & ISDM \\
\hline \multirow{2}{*}{$\frac{\Gamma}{2}$} & Work Process & 0 & ○ & O \\
\hline & Decision Process & 0 & O & $\mathrm{O}$ \\
\hline \multirow{3}{*}{ 嵅 } & Perceived Benefits & 0 & 0 & 0 \\
\hline & Perceived Barriers & O & 0 & 0 \\
\hline & Perceived Risks & 0 & 0 & 0 \\
\hline \multirow{4}{*}{ 这 } & Politics & O & O & ○ \\
\hline & Economics & 0 & 0 & 0 \\
\hline & Legal \& Legislation & ○ & ○ & O \\
\hline & Critical Mass & 0 & ○ & O \\
\hline \multirow{5}{*}{$\frac{x}{6}$} & Managerial Capability & 0 & 0 & 0 \\
\hline & Mutual Goals/Objectives & 0 & 0 & O \\
\hline & Networked Collaboration & 0 & O & 0 \\
\hline & Trust & 0 & 0 & 0 \\
\hline & Financial Matters & 0 & 0 & 0 \\
\hline \multirow{4}{*}{ 项 } & IT Capability & 0 & 0 & 0 \\
\hline & Data Quality & 0 & 0 & 0 \\
\hline & Data Standard & 0 & 0 & 0 \\
\hline & Data Security & O & O & 0 \\
\hline
\end{tabular}

Table 2: Importance of Factors Influencing EIS at LGA_East

\begin{tabular}{|c|l|}
\hline \multicolumn{2}{|c|}{ Pairwise Comparison scale for AHP Preferences } \\
\hline Numerical Rating & \multicolumn{1}{c|}{ Verbal Judgements of Preferences } \\
\hline 1 & A is equally preferred over B \\
\hline 2 & A is equally to moderately preferred over B \\
\hline 3 & A is moderately preferred over B \\
\hline 4 & A is moderately to strongly preferred over B \\
\hline 5 & A is strongly preferred over B \\
\hline 6 & A is strongly to very strongly preferred over B \\
\hline 7 & A is very strongly preferred over B \\
\hline 8 & A is strongly to very extremely preferred over B \\
\hline 9 & A is extremely preferred over B \\
\hline
\end{tabular}

Table 3: Pairwise Comparison scale for AHP Preferences (Source: Saaty, 1980) 


\begin{tabular}{|c|c|c|c|c|c|}
\hline \multirow[b]{2}{*}{ Layers } & \multirow[b]{2}{*}{ Factors } & \multicolumn{4}{|c|}{ Priority Weights } \\
\hline & & HIT & PM & ISM & Global Weight \\
\hline \multirow{2}{*}{$\begin{array}{l}\text { Business Process } \\
\text { Factors }\end{array}$} & WP & 0.6666 & 0.6666 & 0.6666 & $0.6666(1)$ \\
\hline & DP & 0.3333 & 0.3333 & 0.3333 & $0.3333(2)$ \\
\hline \multirow{3}{*}{ BBR Factors } & $\mathrm{PB}$ & 0.5940 & 0.5968 & 0.5940 & $0.5950(1)$ \\
\hline & $\mathrm{PB}^{*}$ & 0.2967 & 0.3347 & 0.2967 & $0.3093(2)$ \\
\hline & PR & 0.1093 & 0.1055 & 0.1093 & $0.1080(3)$ \\
\hline \multirow{4}{*}{$\begin{array}{c}\text { Environmental } \\
\text { Factors }\end{array}$} & $\mathrm{P}$ & 0.1838 & 0.1838 & 0.1764 & $0.1813(2)$ \\
\hline & $\mathrm{E}$ & 0.5732 & 0.5732 & 0.5996 & $0.5820(1)$ \\
\hline & LL & 0.0669 & 0.0669 & 0.0605 & $0.0648(4)$ \\
\hline & $\mathrm{CM}$ & 0.1762 & 0.1762 & 0.1663 & $0.1729(3)$ \\
\hline \multirow{5}{*}{$\begin{array}{l}\text { Organisational } \\
\text { Factors }\end{array}$} & $\mathrm{MC}$ & 0.2774 & 0.2720 & 0.3471 & $0.2988(2)$ \\
\hline & $\mathrm{G} / \mathrm{O}$ & 0.1387 & 0.1360 & 0.0886 & $0.1211(5)$ \\
\hline & $\mathrm{NC}$ & 0.1282 & 0.1074 & 0.1745 & $0.1367(3)$ \\
\hline & $\mathrm{T}$ & 0.1282 & 0.1654 & 0.0844 & $0.1260(4)$ \\
\hline & FM & 0.3274 & 0.3192 & 0.3052 & $0.3172(1)$ \\
\hline \multirow{4}{*}{$\begin{array}{l}\text { Technological } \\
\text { Factors }\end{array}$} & ITC & 0.5750 & 0.5750 & 0.5714 & $0.5738(1)$ \\
\hline & $\mathrm{DQ}$ & 0.1916 & 0.1916 & 0.1428 & $0.1753(2)$ \\
\hline & DS & 0.1916 & 0.1916 & 0.1428 & $0.1753(2)$ \\
\hline & DS* & 0.1916 & 0.1916 & 0.1428 & $0.1753(2)$ \\
\hline
\end{tabular}

Table 4: Individual Importance of Factor Influencing EIS at LGA_North

\begin{tabular}{|c|c|c|c|c|c|}
\hline \multirow[b]{2}{*}{ Layers } & \multirow[b]{2}{*}{ Factors } & \multicolumn{4}{|c|}{ Priority Weights } \\
\hline & & HICT & SISD & ISDM & Global Weight \\
\hline \multirow{2}{*}{$\begin{array}{c}\text { Business Process } \\
\text { Factors }\end{array}$} & WP & 0.7500 & 0.6666 & 0.8000 & $0.7388(1)$ \\
\hline & DP & 0.2500 & 0.3333 & 0.2000 & $0.2611(2)$ \\
\hline \multirow{3}{*}{ BBR Factors } & PB & 0.6243 & 0.3333 & 0.3333 & 0.4303 (1) \\
\hline & PB* & 0.1085 & 0.3333 & 0.3333 & $0.2584(3)$ \\
\hline & PR & 0.2672 & 0.3333 & 0.3333 & $0.3112(2)$ \\
\hline \multirow{4}{*}{$\begin{array}{c}\text { Environmental } \\
\text { Factors }\end{array}$} & $\mathrm{P}$ & 0.2807 & 0.3333 & 0.1838 & $0.2660(2)$ \\
\hline & $\mathrm{E}$ & 0.4314 & 0.3333 & 0.5732 & $0.4459(1)$ \\
\hline & LL & 0.1102 & 0.1667 & 0.0669 & 0.1146 (4) \\
\hline & $\mathrm{CM}$ & 0.1775 & 0.1667 & 0.1762 & 0.1734 (3) \\
\hline \multirow{5}{*}{$\begin{array}{l}\text { Organisational } \\
\text { Factors }\end{array}$} & $\mathrm{MC}$ & 0.3193 & 0.3171 & 0.2720 & $0.3028(1)$ \\
\hline & $\mathrm{G} / \mathrm{O}$ & 0.1082 & 0.1185 & 0.1360 & 0.1209 (4) \\
\hline & $\mathrm{NC}$ & 0.0925 & 0.1185 & 0.1074 & $0.1061(5)$ \\
\hline & $\mathrm{T}$ & 0.2243 & 0.2085 & 0.1654 & 0.1994 (3) \\
\hline & FM & 0.2556 & 0.2371 & 0.3192 & $0.2706(2)$ \\
\hline \multirow{4}{*}{$\begin{array}{l}\text { Technological } \\
\text { Factors }\end{array}$} & ITC & 0.3452 & 0.3944 & 0.5714 & $0.4370(1)$ \\
\hline & DQ & 0.2307 & 0.2513 & 0.1428 & $0.2083(2)$ \\
\hline & DS & 0.1760 & 0.1819 & 0.1428 & 0.1669 (4) \\
\hline & DS* & 0.2480 & 0.2097 & 0.1428 & $0.2002(3)$ \\
\hline
\end{tabular}

Table 5: Individual Importance of Factor Influencing EIS at LGA_East 


\begin{tabular}{|c|c|c|c|}
\hline \multirow[b]{2}{*}{ Layers } & \multirow[b]{2}{*}{ Factors } & \multicolumn{2}{|c|}{ Comparison of Priority Weights } \\
\hline & & $\begin{array}{c}\text { Global Weight for } \\
\text { LGA_North }\end{array}$ & $\begin{array}{c}\text { Global Weight for } \\
\text { LGA_East }\end{array}$ \\
\hline \multirow{2}{*}{$\begin{array}{c}\text { Business Process } \\
\text { Factors }\end{array}$} & WP & $0.6666(1)$ & $0.7388(1)$ \\
\hline & $\mathrm{DP}$ & $0.3333(2)$ & $0.2611(2)$ \\
\hline \multirow{3}{*}{ BBR Factors } & $\mathrm{PB}$ & $0.5950(1)$ & $0.4303(1)$ \\
\hline & $\mathrm{PB}^{*}$ & $0.3093(2)$ & $0.2584(3)$ \\
\hline & PR & $0.1080(3)$ & $0.3112(2)$ \\
\hline \multirow{4}{*}{$\begin{array}{c}\text { Environmental } \\
\text { Factors }\end{array}$} & $\mathrm{P}$ & $0.1813(2)$ & $0.2660(2)$ \\
\hline & $\mathrm{E}$ & $0.5820(1)$ & $0.4459(1)$ \\
\hline & LL & $0.0648(4)$ & $0.1146(4)$ \\
\hline & $\mathrm{CM}$ & $0.1729(3)$ & $0.1734(3)$ \\
\hline \multirow{5}{*}{$\begin{array}{c}\text { Organisational } \\
\text { Factors }\end{array}$} & $\mathrm{MC}$ & $0.2988(2)$ & $0.3028(1)$ \\
\hline & $\mathrm{G} / \mathrm{O}$ & $0.1211(5)$ & $0.1209(4)$ \\
\hline & $\mathrm{NC}$ & $0.1367(3)$ & $0.1061(5)$ \\
\hline & $\mathrm{T}$ & $0.1260(4)$ & $0.1994(3)$ \\
\hline & FM & $0.3172(1)$ & $0.2706(2)$ \\
\hline \multirow{4}{*}{$\begin{array}{l}\text { Technological } \\
\text { Factors }\end{array}$} & ITC & $0.5738(1)$ & $0.4370(1)$ \\
\hline & DQ & $0.1753(2)$ & $0.2083(2)$ \\
\hline & DS & $0.1753(2)$ & $0.1669(4)$ \\
\hline & $\mathrm{DS}^{*}$ & $0.1753(2)$ & $0.2002(3)$ \\
\hline
\end{tabular}

Table 6: Comparison of Factor Influencing EIS at LGA_North and LGA_East 